\title{
Las noticias en la pantalla rioplatense: análisis de la estructura de los telenoticieros en Uruguay y Argentina
}

The news on the screen rioplatense: analysis of the structure of the newscasts in Uruguay and Argentina

\author{
Melina de la Barrera Ayres \\ (melina.ayres@gmail.com) ${ }^{l}$ \\ http://dx.doi.org/10.5216/cei.v15i1.22501
}

\begin{abstract}
Resumen
El presente texto presenta los resultados de la investigación realizada en la Maestría en Periodismo de la Universidad Federal de Santa Catarina, Brasil, en 2009. La investigación se apoya en un estudio de caso múltiple, de dos telenoticieros de países del Rio de la Plata: Telemundo Edición Central, de Teledoce, de Uruguay, y Telenueve $2^{a}$ Edición, de Canal 9, Argentina. El estudio parte de una noción de estructura como organización espacio-temporal, del producto periodístico y de su proceso de producción. La primera etapa implicó el relevamiento de los elementos que componen un telenoticiero, divididos en tres grandes grupos: elementos de edición, elementos de lenguaje y actores. La segunda persiguió el objetivo de disecar la estructura del producto, partiendo de una visión macro (analizando los elementos de edición) y una visión micro (analizando los elementos del lenguaje). Finalmente, para explicar la estructura de los productos, y partiendo de la idea de que las noticias son el resultado de un proceso de producción, selección y transformación de una materia prima - los hechos-, se realizó también, una observación del proceso de producción (aplicando la metodología de newsmaking) y entrevistas con algunos de los profesionales del equipo de cada uno de los telenoticieros.
\end{abstract}

Palabras-clave: Telenoticiero. Estructura. Productos Periodísticos. Uruguay. Argentina.

\begin{abstract}
This paper presents the results of research conducted in the Masters in Journalism at the Federal University of Santa Catarina, Brazil, in 2009. The research is based on a multiple case study, two newscasts from countries of the Rio de la Plata: Telemundo Central Edition of Teledoce, of Uruguay, and Telenueve 2nd Edition, Channel 9, Argentina. The study is based on a notion of structure and spatiotemporal organization, the journalistic product and its production process. The first stage involved the survey of the elements of a newscast, divided into three main groups: elements editing, language elements and actors. The second pursued the aim to dissect the structure of the product, from a macro perspective (analyzing elements of publication) and a micro view (analyzing the elements of language). Finally, to explain the structure of the products and starting from the idea that the news is the result of a process of production, selection and conversion of a raw material - the facts-, was also performed, an observation of the production process (applying the methodology newsmaking) and interviews with some of the team professionals each newscasts.
\end{abstract}

Keywords: Newscast. Structure. Journalistic Products. Uruguay. Argentina.

\footnotetext{
1 Doutoranda do Programa de Pós-Graduação Interdisciplinar em Ciências Humanas, Universidade Federal de Santa Catarina, Florianópolis.
} 


\section{Introdução}

Os telejornais fazem parte do cotidiano de todas as pessoas, nos quatro cantos do planeta. Esses noticiários são os produtos jornalísticos de maior audiência: em primeiro lugar, porque são fonte de acesso fácil aos acontecimentos diários; em segundo lugar, porque esse acesso é econômico; e, em terceiro lugar, porque não é necessário ir muito longe para informar-se, basta caminhar até a sala e ligar a televisão (VIZEU, 2006a, 2006b, 2005).

O reconhecimento dessas características do telejornal impulsionou a realização da pesquisa de Mestrado "Diversidade na tela: um estudo sobre a estrutura dos telejornais no Uruguai e na Argentina”, entre 2007 e 2009, na Universidade Federal de Santa Catarina, Brasil. O objetivo deste artigo é, portanto, apresentar a pesquisa, sua metodologia e alguns dos resultados alcançados.

A pesquisa versou sobre o seguinte problema: Como se estruturam ${ }^{2}$ os telejornais platinos? Como objetos deste estudo foram selecionados dois telejornais: Telemundo Edición Central (TLMEC), do canal uruguaio Teledoce, e Telenueve Segunda Edición (TL9 $2^{\circ} E d$ ), do Canal 9, da Argentina. Esses noticiários são exibidos no horário nobre (19h às $22 \mathrm{~h}$ ), têm alcance nacional e conteúdo multitemático (economia, esportes, política, cidadania etc.). A escolha destes telejornais justifica-se, pelo seu alcance e sua audiência. No momento em que a pesquisa foi realizada TLM-EC era o telejornal mais visto do Uruguai, com 11 pontos no índice de audiência (IBOPE Uruguai, 2/07/08) ${ }^{3}$, e $T L 92^{\circ} E d$, disputava com América Notícias o segundo lugar no IBOPE, obtendo 9.1 pontos (IBOPE Argentina, 9/07/2008). ${ }^{4}$

\section{Revisando o conceito: o que é um telejornal?}

Diversos autores buscaram definir o telejornal, entre eles Aronchi, que o entende como “[...] um programa que apresenta características próprias e evidentes, com o apresentador em estúdio chamando matérias e reportagens sobre os fatos mais recentes" (2004, p.149). Conforme Charadeau, o telejornal "[...] é o gênero que integra o maior número de formas televisuais como: anúncios, reportagens, resultados de pesquisas e de investigações, entrevistas, minidebates, análises de especialistas etc.” (2006, p.227). Segundo Álvarez, o telejornal é "um programa jornalístico que

\footnotetext{
2 A estrutura é entendida como organização espaço-temporal, que se expressa no processo e produto jornalístico, neste caso, o telejornal.

3 Segundo o Ibope Uruguai, no país, cada ponto do raiting equivale a 11.942 indivíduos ou 4.396 lares. A medição é feita somente em Montevidéu. Disponível em: 〈www.ibope.com.uy>. Acesso em: mar. 2009.

4 Segundo o IBOPE Argentina, no país, cada ponto do raiting equivale a 30.706 lares ou 96.782 indivíduos. A medição é feita somente na Grande Buenos Aires. Disponível em: <www.ibope.com.ar>. Acesso em: mar. 2009.
} 
relata, dia-a-dia, os acontecimentos ocorridos desde sua última edição [...] constitui um gênero amplamente expandido no mundo [...]” (1988, p.17).

Cada uma dessas descrições aponta alguns aspectos que definem o telejornal: é um programa de TV, é um programa jornalístico, funciona com estúdio e apresentador, aborda temas atuais, fatos do dia, tem relação íntima com a realidade, inclui diversas formas televisuais, como reportagens, entrevistas etc. Esses aspectos fazem parte do telejornal, porém, não são os únicos.

Buscando definir o telejornal, segue-se aqui a proposta de Bakhtin, que, ao analisar o processo de criação literária, afirma que "o autor é orientado pelo conteúdo, ao qual ele dá forma e acabamento, por meio de um material determinado [...]. A forma depende, de um lado, do conteúdo e, do outro, das particularidades do material e da elaboração que este implica" (1992, p.206). Como argumenta Meditsch, "a natureza do material determina limites e possibilidades para o seu uso enquanto linguagem [...]” (2001, p.216). Seguindo-se essas noções, pode-se afirmar que o telejornal é um produto televisivo, ${ }^{5}$ que combina conteúdo jornalístico com material audiovisual.

O conteúdo do telejornal é o conteúdo do gênero jornalístico, que é um dos gêneros do discurso considerados referenciais. Dizer que o conteúdo do telejornal é de um gênero referencial supõe que ele "[...] fala de algo do mundo, exterior ao emissor, ao receptor e ao processo de comunicação em si” (LAGE, 1998, p.39). Jakobson (1969) distingue seis funções básicas da comunicação: emotiva, referencial, poética, fática, metalingüística e conativa. Em toda comunicação, as seis funções podem estar presentes, porém, sempre há uma dominante. No jornalismo, assim como na ciência, predomina a função referencial. Segundo Vizeu, o predomínio da função referencial no jornalismo "pressupõe a veracidade dos fatos a que se refere e a autenticidade do seu relato" (2003, p.114). Nessa mesma perspectiva, Meditsch afirma que "[...] o jornalismo tem, como ideal, a reprodução fiel de uma realidade exterior à que se refere" (2001, p.175).

O material do telejornal é audiovisual, o que implica a presença de determinados elementos de linguagem, que, segundo Cebrián (1978), são: a) imagem e som; b) imagem e som combinados de alguma forma e com certa interdependência; c) oferecer uma realidade perceptível pela vista e pelo ouvido, reproduzida por um sistema técnico, o que resultará numa realidade recortada, selecionada por limites bem definidos: campo ocupado pela lente da câmara ou ambiente sonoro recolhido por um microfone etc. O telejornal regula-se pelas características e formas da técnica da linguagem

5 O telejornal é um produto, pois resulta de um processo de produção (VILCHES, 1989). 
audiovisual utilizada (CEBRIÁN, 1992, p.23-24) e suas possibilidades estão determinadas por essa linguagem.

Na televisão a linguagem organiza-se fundamentalmente no tempo. A televisão caracterizase pela fugacidade, "é um texto irreversível, o que o diferencia de todas as linguagens fixas: escritura, pintura, fotografia etc.” (CEBRIÁN, 1983, p.67). Mas também há nesse meio, segundo Cebrián, uma dimensão espacial: "existe um componente espacial que o diferencia, por exemplo, da linguagem radiofônica, não obstante, este espaço está limitado significativamente pelo tempo" (1983, p.67).

O espaço no telejornal entende-se como o lugar onde se expressam o plano da imagem e o plano sonoro. Álvarez afirma que "a noção de espaço vincula-se essencialmente ao visual, por mais que exista também uma espacialidade criada pela codificação de distâncias sonoras” (1988, p.51).

O telejornal, portanto, é um produto televisivo, resultante da confluência do gênero jornalístico e do material audiovisual, mas sua definição não se limita a essas questões. O telejornal tem determinados elementos que o caracterizam, e o modo como se utilizam esses elementos também é convencionado.

\section{Metodologia}

A metodologia proposta nesta pesquisa busca desvendar como se estruturam os telejornais. Para tanto, a análise centra-se na estrutura do produto de cada um dos telejornais, levando em conta o seu processo de produção. Destaca-se que a análise do processo subordina-se à análise do produto.

Como citado anteriormente, por estrutura entende-se a organização espaço-temporal, que se expressa no processo e produto jornalístico - telejornal. A estrutura do produto define-se por meio “dos elementos utilizados na sua composição" (MARQUES DE MELO, 1973, p.134). No telejornal, a estrutura é uma sequência lógica que possibilita a organização e ordenação das notícias (por exemplo, os blocos, a ordem interna das reportagens etc.).

Para analisar a estrutura do produto foi elaborada uma metodologia específica, que permite observar de forma integrada o plano sonoro e o da imagem do telejornal. Esse modo de observar os planos da imagem e o sonoro foi aplicado ao cinema, em diversas oportunidades, porém, não é um método comumente utilizado na análise de telejornais (CHION, 1993; ÁLVAREZ, 1988; CEBRIÁN, 1983). 
Para a análise do produto, primeiramente, reuniram-se os elementos que compõem a estrutura do telejornal, divididos em três grupos: elementos da edição, elementos de linguagem e atores.

Figura 1 - Elementos do telejornal: elementos da edição

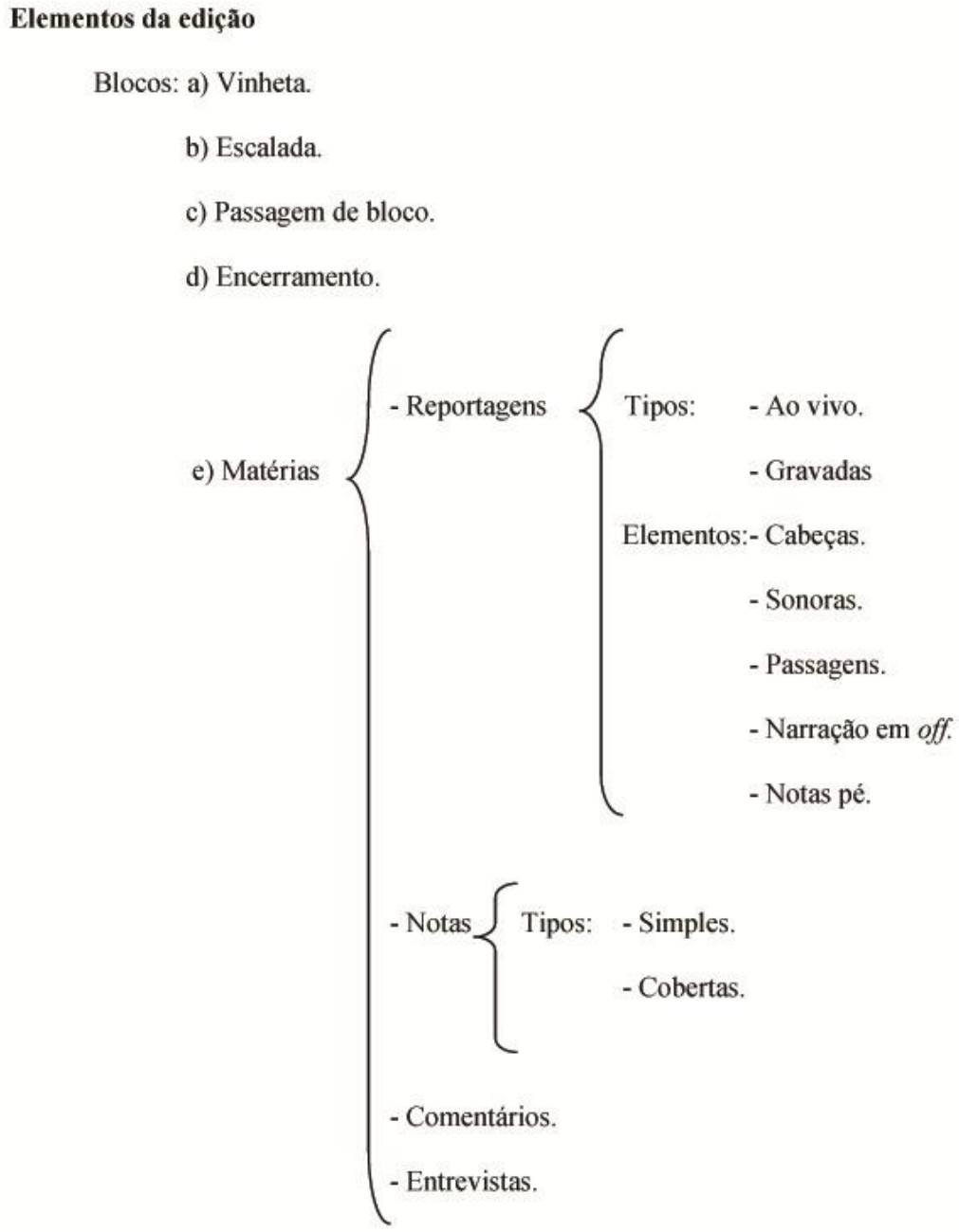


Figura 2 - Elementos do telejornal: elementos de linguagem e os atores

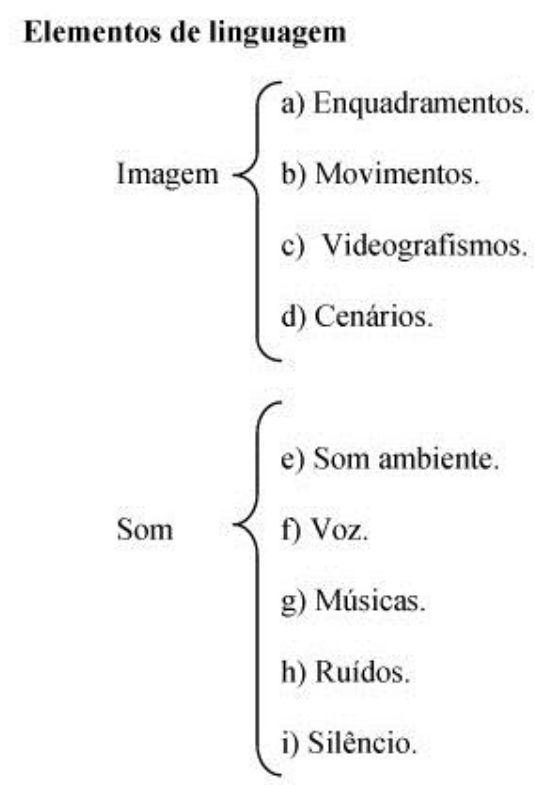

Audiovisual: j) Combinação dos elementos da imagem e som.

\section{Os atores}
a) Apresentadores.
b) Repórteres.
c) Comentaristas / especialistas.
d) Locutor impessoal.

Para verificar esses elementos e dissecar a estrutura do produto, adotaram-se duas visões: uma macro e outra micro, que possibilitaram a análise do telejornal a partir de óticas distintas. Na macrovisão, observaram-se os elementos da edição e, na microvisão, os elementos de linguagem.

A macrovisão permite observar os elementos da edição e a forma como eles se ordenam dentro da estrutura do telejornal, ou seja, dentro de seus blocos. 
Figura 3 - Macrovisão do telejornal

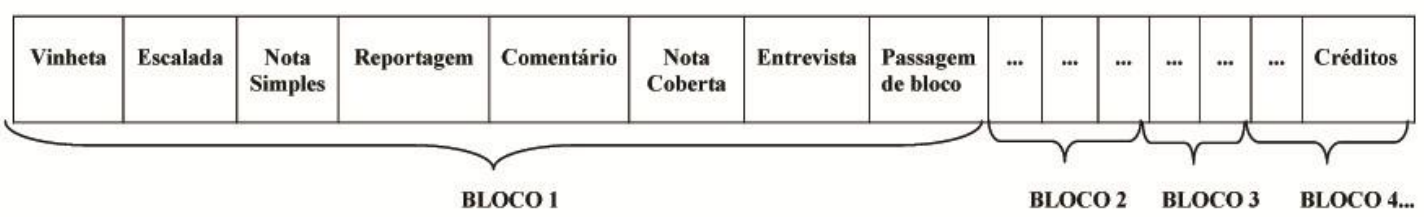

A microvisão permite realizar análise mais detalhada dos componentes de imagem e som. Nessa visão, fazem-se dois tipos de "corte" no produto: um corte horizontal, que permite analisar plano a plano a imagem e o som, e um corte vertical, que permite observar os diversos elementos da linguagem do telejornal e como eles se relacionam entre si.

Figura 4 - Microvisão do telejornal

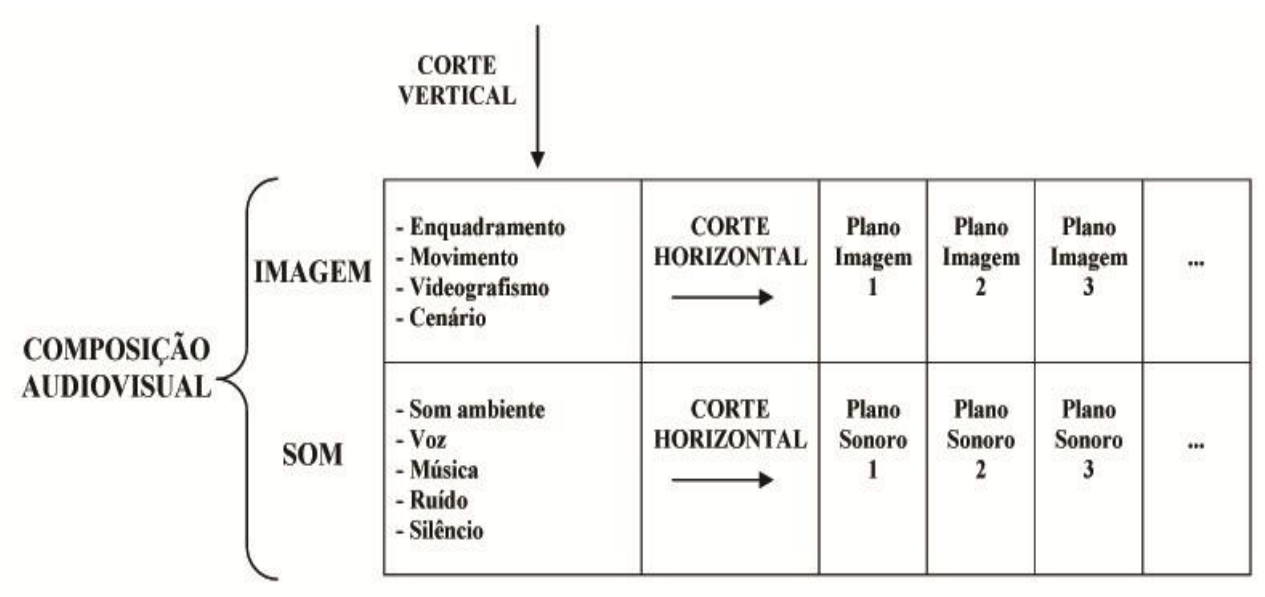

A essas duas visões acrescentou-se uma análise sobre os atores (apresentadores, repórteres, comentaristas) dos telejornais.

A análise da estrutura dos telejornais esteve acompanhada por uma observação do processo de produção, realizada durante uma semana em cada uma das redações. Estas observações do que acontecer "por trás das câmeras", permitiram explicar o que se vê na tela da TV.

\section{Telemundo Edición Central - Uruguai}

Com quatro edições de segunda à sexta-feira e uma aos domingos, TLM-EC conta com um quadro profissional dividido em equipe jornalística e equipe técnica. A equipe jornalística é 
formada por dois apresentadores, duas produtoras, quatro repórteres que trabalham na rua (um deles se dedica exclusivamente aos esportes), um editor de texto e quatro especialistas - internacional, espetáculo, esporte e meteorologia. A equipe técnica é formada por quatro cinegrafistas, três editores de imagem, três motoristas e um técnico. Neste telejornal não se trabalha especificamente com editorias, porém, alguns repórteres costumam dedicar-se a certas áreas, como política, polícia, assuntos internacionais e cultura. O único setor que trabalha como uma editoria é o de esporte, que tem certa independência em relação ao resto da equipe.

Para a produção das notícias $T L M-E C$ recorre, em primeiro lugar, aos telejornais veiculados pela emissora durante o dia. Geralmente, são tiradas dali algumas matérias, que são refeitas, pois são acrescentados novos dados. Releases e newsletters do governo e de empresas são fonte significativa de dados. Outras fontes importantes são os sítios na internet e os jornais nacionais. Para as matérias internacionais, TLM contratou o serviço do Newsourse, Agência $F$ e um serviço limitado de $A P T N$. No entanto, também grava, apesar de saber que não é legal, material de programas brasileiros, como Globo Esporte da Rede Globo, de emissoras da Espanha, como Antena 3, e argentinas, como $T N$. No que se refere ao arquivo, que muitas vezes é um recurso fundamental para retomar ou relembrar fatos ocorridos no passado, TLM e Teledoce possuem um arquivo precário. Para se ter uma ideia, com o advento da televisão colorida, o proprietário da emissora mandou destruir todas as fitas em preto e branco, pois elas ocupavam espaço e já não seriam utilizadas. Essa situação continua se repetindo, a emissora guarda todos seus programas gravados na íntegra somente por uma semana, inclusive o telejornal, e o TLM nunca arquiva suas edições completas. São escolhidas algumas matérias que se acredita que poderão ser reutilizadas, o resto é apagado. Questionado sobre essa situação, o gerente de notícias afirmou que se guarda somente 50 por cento do material, principalmente boas imagens, e que é consciente da perda diária de material e de como isso dificulta o trabalho no futuro.

TLM tem correspondentes em oito dos dezenove departamentos do país e nenhum no exterior. Outro aspecto importante da estrutura de captação é que os assuntos relacionados à política e polícia são muito valorizados no telejornal e, somente nessas áreas, há profissionais exclusivamente encarregados de prover informações. No caso da política, há um repórter que trabalha somente no Parlamento, para os assuntos relacionados à polícia, o telejornal paga a um policial aposentado para que passe o dia inteiro escutando a rádio da polícia de Montevidéu. Se houver algum fato importante, ele liga para a redação, que envia uma equipe ao local. 
Para se ter uma ideia da importância das matérias policiais e políticas no TLM, segundo o gerente de notícias, Alfonso Lessa, o telejornal sempre tem de começar com elas: "Estas notícias são o ponto forte e, no total, dedicamos a elas quase vinte minutos diários" (04/07/2008)

Ao analisar a estrutura do TLM-EC a partir da macrovisão observam-se os elementos de edição e percebe-se que ele tem uma estrutura básica que se repete em cada edição: quatro blocos de notícias com uma duração aproximada de 50 minutos e a organização em blocos temáticos, organizados do seguinte modo:

Primeiro bloco - notícia do dia + polícia e política

Segundo bloco - assuntos internacionais

Terceiro bloco - economia

Quarto bloco - esporte + cultura + previsão do tempo

Cada um dos quatro blocos dedica-se quase exclusivamente a uma ou duas temáticas. Essa forma de organização dá simplicidade e agilidade ao telejornal.

No que se refere aos tipos de matéria, o mais utilizado é a reportagem. As notas simples ou cobertas também estão presentes, porém só são utilizadas em situações pontuais, como é o caso da cotação das moedas e outras matérias de economia. Os comentários aparecem somente nas notas pé de algumas reportagens de esporte, e são feitos por seu especialista. Já a entrevista em estúdio quase não é utilizada. Na semana analisada, excepcionalmente, com a liberação de Ingrid Betancourt, a embaixadora da Colômbia no Uruguai foi entrevistada por Aldo Silva no estúdio. As entrevistas sempre são feitas "na rua" e aparecem com o objetivo de confirmar ou acrescentar algum dado à informação que está sendo apresentada na reportagem.

Um aspecto interessante desse noticiário, no que diz respeito aos tipos de matérias, é o que chamam de "notícias breves" (notícias que aparecem em texto de cinco ou seis linhas acompanhadas pelo off do locutor do telejornal) e "puesta a punto" (resumo das principais matérias do dia). Os links ao vivo são utilizados em poucas ocasiões. Normalmente se faz link com o Parlamento (localizado em Montevidéu, mesma cidade onde está o estúdio do telejornal). Essa situação explica-se pelo alto custo desse tipo de transmissão e, de certa forma, demonstra as dificuldades econômicas da emissora. O gerente de notícias explica a situação: "Os links ao vivo são importantes, mas somos o único canal que não tem unidades de satélite, temos microondas e muitas vezes estamos onde podemos e não onde queremos" (LESSA, 04/07/2008). 
A partir da microvisão observou-se que TLM-EC busca, sempre que possível, obter imagens de qualidade e manter certos padrões. Isso se evidencia, por exemplo, no uso do Plano Geral para contextualizar, no uso constante do Plano Médio no estúdio e nas entrevistas na rua e na busca por imagens com boa iluminação. No entanto, há alguns elementos que fazem com que o TLM-EC não tenha unidade no plano das imagens. Dentre eles, destaca-se a falta de imagens, quando se trata de fatos internacionais, o que leva a uma infinita cópia de imagens e sons de outras emissoras. O resultado disso é um telejornal que sobressai nas matérias locais, mas perde qualidade nas internacionais. Essa perda de qualidade é, em alguns momentos, "dissimulada" pela presença de um especialista, que acrescenta a visão de TLM-EC sobre os fatos.

Como exemplo pode citar-se o dia 2 de julho de 2008, quando Ingrid Betancourt foi liberada. Ao longo da edição todas as imagens sobre o assunto foram copiadas de outras emissoras. Em uma das notas cobertas se chega ao extremo de não se saber qual foi a primeira emissora a veicular as imagens, como pode ser ver na Figura 6.

Figura 6 - TLM: reportagem sobre Betancourt
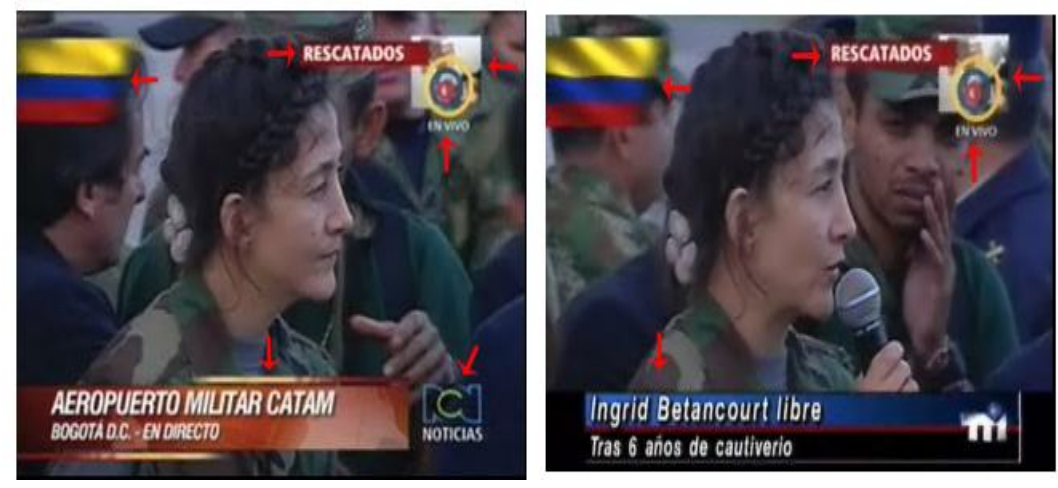

Assim como as imagens, os sons das matérias captadas de outras emissoras muitas vezes também são mantidos. Na edição do dia 2 de julho, veiculou-se, por exemplo, uma reportagem da CNN sobre o discurso do presidente francês Nicolas Sarkozy, em resposta à liberação de Betancourt. Essa reportagem manteve o som original da $C N N$, o único elemento acrescentado pelo $T L M-E C$ foi sua listra característica com o texto: "Ingrid Betancourt livre" (02/07/2008).

O TLM-EC não está preparado para cobrir acontecimentos internacionais inesperados. As matérias do dia 2 de julho de 2008 evidenciam carência de imagens e nenhum recurso de arquivo. O 
resultado foi uma edição repleta de imagens e sons de outras emissoras, uma espécie de "recorte e cole".

Com relação aos atores, destaca-se a constante presença dos especialistas, que não só aparecem como expertos em determinadas áreas, mas também apresentam matérias e opinam.

Fica claro, em alguns casos, como decisões ou situações ocorridas por trás das câmeras refletem no produto final. A falta de um bom arquivo é, sem dúvida, resultado de carências econômicas e de uma decisão empresarial, que leva a que muitas vezes não haja imagens, sons ou músicas para editar as matérias. O resultado disso é falta de unidade tanto no plano da imagem como no sonoro.

\section{Telenueve $2^{\circ}$ Edición - Argentina}

Por ter quatro edições diárias, Telenueve (TL9) possui equipe de aproximadamente 150 profissionais, que se revezam de acordo com os horários de veiculação dos telejornais. A presente pesquisa centra-se no principal telejornal do Canal 9, Telenueve $2^{a}$ Edición (TL9 $2^{\circ} E d$ ), por isso, será descrita somente essa equipe que está composta por dois grandes grupos de profissionais, um que fica dentro da redação e outro que trabalha na rua.

No grupo que fica dentro da redação estão, o diretor de notícias, Emilio Gimenez Zapiola, um produtor executivo, um subprodutor executivo, um chefe de produção, três produtores-redatores (dentre eles, um se encarrega das notícias internacionais e outro, das notícias de esportes), um responsável pelo script, dois chefes de editores de imagem (que se revezam e também editam), quatro editores de imagem, quatro pessoas encarregadas de produzir os videografismos, um responsável pelo arquivo, um responsável por receber as imagens do satélite e dois locutores. ${ }^{6}$ Além disso, há uma equipe de dez pessoas responsáveis pela elaboração de reportagens especiais, composta por editores de imagem, cinegrafistas e repórteres.

O grupo que trabalha na rua divide-se em equipes. No total, são nove equipes compostas por um repórter e um cinegrafista, que também é o motorista. O material produzido na rua pode chegar à emissora de duas formas: mais comum é que a equipe leve o XD-CAM (disco digital de câmera) para a redação e descarregue a informação lá, mas, quando há pressa ou link ao vivo, utilizam-se antenas de microondas.

\footnotetext{
6 A função do locutor é gravar offs de matérias que são totalmente produzidas dentro da redação, como, por exemplo, as internacionais.
} 
Além dessas equipes, no momento em que foi realizada a pesquisa, TL9 $2^{\circ} E d$ tinha um repórter e um cinegrafista dedicados exclusivamente a produzir uma série de reportagens, veiculadas todas as sextas-feiras, sobre cidades do interior da Argentina: "Pueblo mío". Esta equipe trabalhava com total independência das demais equipes de reportagem. O repórter decidia as cidades que seriam visitadas e os temas a tratar.

A esses dois grandes grupos acrescenta-se o apresentador, Cláudio Rigoli, que somente vai à redação buscar o script do telejornal. De certa forma, ele é a "cara das notícias" da emissora. Além de Rigoli, o especialista de esportes e o de polícia, também ocupam a bancada e, quando se apresentam reportagens especiais, aparece no estúdio algum repórter da equipe que produziu a reportagem para fazer comentários e acrescentar informações.

As notícias de $T L 92^{\circ} E d$ são produzidas a partir de, em primeiro lugar, os telejornais veiculados nesse mesmo dia em horários anteriores - Telenueve al Amanecer e Telenueve $1^{a}$ Edición. Na semana em que foi realizada a observação, todas as matérias que foram reutilizadas dos noticiários anteriores não foram modificadas nem no conteúdo nem na forma. Os sítios da Internet, releases e newsletters, tanto do governo como de empresas, e os sete principais jornais do país são outras fontes de informação. Além disso, TL9 tem correspondentes em 23 cidades de diversas províncias. Apesar da quantidade de correspondentes, a maioria das províncias do extremo norte e sul do país não tem nenhum repórter, o que muitas vezes impossibilita a divulgação dos fatos ocorridos ali.

O telejornal também compra pacotes de agências de notícias, como AP, Newsourse e APTN, que são fundamentais para as notícias internacionais. O TL9 não tem correspondentes em outros países e praticamente nunca envia seus repórteres ao exterior. Outras fontes de informação e, principalmente, de imagens, são as emissoras "aliadas" C5 e TV26, canais de cabo de notícias, e as imagens de três câmeras colocadas pelo Governo da Província de Buenos Aires em pontos estratégicos da capital. As imagens dessas câmeras são de alta qualidade (não são câmeras de controle de trânsito ou da polícia) e são cedidas gratuitamente para todas as emissoras da cidade.

Aspecto interessante da estrutura de captação de notícias é que o TL9 trabalha muito com ligações telefônicas da audiência, a tal ponto de, durante a veiculação do telejornal, aparece na tela um número de telefone para que o público ligue e faça denúncias. Segundo o produtor responsável por atender a esses telefonemas, $75 \%$ das ligações passam informações importantes para o telejornal. Isso faz do telefone ferramenta fundamental de captação e verificação de notícias. 
Da análise da estrutura deste telejornal a partir da macrovisão, observa-se, em primeiro lugar, a organização em blocos. $T L 92^{\circ} E d$ tem uma estrutura básica que se repete diariamente: dura entre 48 e 50 minutos (sem contar os breaks) e está dividido em três blocos que não tem uma duração regular. Em algumas edições, o bloco mais longo é o primeiro, em outras, é o segundo ou o terceiro. Certo é que sempre o bloco mais longo dura entre 25 e 30 minutos. Este telejornal não trabalha com blocos temáticos, de modo que, a estrutura e a ordem de apresentação das matérias varia todos os dias.

Os elementos dos blocos que sempre estão presentes são: o primeiro bloco que, começa sempre com a escalada - lá chamada de "Ventas" - sem vinheta prévia. A quantidade de matérias escolhidas para a escalada varia entre quatro e sete. As passagens de bloco são feitas no final de cada bloco (à exceção do último), e não são lidas pelo apresentador. A vinheta somente aparece no final do primeiro bloco e no começo e final dos blocos seguintes.

Outro aspecto comum a todas as edições do $T L 92^{\circ} \mathrm{Ed}$, é uma propaganda de autopromoção ${ }^{7}$ que não sempre se veicula no mesmo bloco. O telejornal divulga um número de telefone para que os telespectadores liguem e façam denúncias ou avisem sobre fatos ocorridos.

Da microvisão destaca-se também que, dentre as matérias, a reportagem é o formato de mais utilizado, 76,5\% do total. A presença diária das reportagens especiais marca uma característica do produto, que também se vê na produção, pois há uma equipe específica para produzir esse tipo de reportagem. Outro aspecto ligado às reportagens especiais é que, logo após sua veiculação, aparece no estúdio um repórter responsável por sua produção e conversa com o apresentador sobre o assunto. Esse repórter não é especialista, porém, aparece como "conhecedor" do assunto abordado.

Vale destacar que TL9 $2^{\circ} E d$ não só não tem estrutura fixa para os blocos como não segue ordem de apresentação preestabelecida. A ordenação e a hierarquização das diversas matérias se realizam de modo particular. Por exemplo, no dia 7 de julho de 2008, o terceiro bloco do telejornal começou com uma reportagem sobre um bebê com síndrome de Down, seguida de uma nota coberta sobre o nascimento do filho de Nicole Kidman. Depois, Rigoli apresentou uma compilação de notícias que reunia três assuntos: um jornalista roubado na rua, a aterrissagem forçada do avião de Obama e o processo contra um torturador da ditadura militar. Este exemplo evidencia que a ordenação das matérias não distingue os temas tratados. Questionado sobre isto, o diretor de

\footnotetext{
${ }^{7}$ A autopromoção é uma forma específica de publicidade. Segundo a lei de televisão portuguesa (Lei n. 27/2007, de 30 de julho) a autopromoção é "a publicidade difundida pelo operador de televisão relativa aos seus próprios produtos, serviços, serviços de programas televisivos ou programas [...]” (PORTUGAL, 2009).
} 
notícias respondeu: “Os (programas) jornalísticos na televisão não devem ser como nos jornais. Nós misturamos tudo. Não há seções" (ZAPIOLA, 10/07/2008).

A partir da microvisão observou-se que este noticiário dá tratamento especial a imagens e sons de suas reportagens, principalmente quando se trata de reportagens especiais. No que diz respeito às imagens, é difícil ver imagens captadas de outras emissoras. TL9 busca alternativas, utiliza imagens de celulares, de câmeras de segurança e até baixa imagens do Youtube. Logicamente, a qualidade dessas imagens não é a mesma daquelas gravadas pelos cinegrafistas, mas é uma saída viável. Os videografismos são outro elemento presente. Eles cumprem diversas funções, como título das matérias, acrescentam informações, destacam dados, dão dinamismo às reportagens.

No plano sonoro, destaca-se a presença constante da música. Ela está presente na vinheta, na escalada, na apresentação das matérias, em todas as reportagens e notas cobertas e também nas passagens de bloco.

No que diz respeito aos atores, é evidente a intenção do TL9 de mostrar os profissionais de sua equipe. Isto se evidencia nas reportagens, quando eles aparecem fazendo as entrevistas, conversando com as pessoas e fazendo as passagens, e principalmente pela constante presença no estúdio do telejornal, lugar geralmente reservado aos apresentadores e especialistas.

TL9 $2^{\circ} E d$ é um telejornal tipicamente argentino. Todos os telejornais do país têm características similares às do TL9. Eles misturam jornalismo com entretenimento ou, como afirma o chefe de editores do telejornal, "jornalismo e show".

\section{Dois países, dois telejornais.}

A análise por meio da macrovisão permitiu concluir que, apesar de que os dois telejornais analisados tem uma duração aproximada de 50 minutos (sem contar os breaks), sua estrutura é bastante diferente. TLM-EC (Uruguai) distribui o seu tempo no ar em quatro blocos temáticos e tem estrutura estável, que se repete a cada edição. Enquanto que $T L 92^{\circ} E d$ (Argentina), divide o seu tempo em três blocos que têm sua duração e estrutura interna diferente a cada edição. Essa instabilidade se deve a que o telejornal acaba sendo montado ao vivo, apesar de haver um script a seguir. O produtor executivo muda a ordem da entrada no ar das matérias, no momento da veiculação do telejornal, tendo em conta as matérias que são veiculadas pelos telejornais das emissoras concorrentes, seus breaks e os índices de audiência, obtidos por cada um dos programas 
minuto a minuto. No telejornal uruguaio, a ordem prevista para algumas matérias também é modificada na veiculação do telejornal. O coordenador jornalístico muda a ordem, tendo em consideração as matérias veiculadas pelo concorrente, Subrayado, do Canal 10, ou matérias que ainda estão sendo editadas, porém, sempre se mantém o critério dos blocos temáticos.

Os índices de audiência são preocupação permanente nos dois telejornais. Na Argentina, se trabalha com o minuto a minuto, no momento da veiculação do telejornal. No Uruguai, os resultados dos índices de audiência minuto a minuto chegam ao gerente de notícias somente na manhã seguinte.

Ao comparar a estrutura desses dois produtos a partir da macrovisão, encontraram-se elementos que sempre aparecem no mesmo lugar. Esse é o caso da escalada, do encerramento, e das passagens de bloco, exceto do último.

Os anúncios publicitários dentro dos blocos são outro elemento presente na estrutura dos dois telejornais. TLM-EC tem, em média, 11 anúncios diariamente, que aparecem em todos os blocos e inclusive entre uma matéria e outra. São comerciais de todo tipo de produtos: remédios, canetas, alimentos, etc. Todos esses comerciais juntos ocupam cerca de 5 minutos do programa. Questionado sobre esse aspecto, Lessa respondeu: "É uma realidade com que temos de conviver. Esse meio é uma empresa e precisa vender publicidade por diversas circunstâncias. É, entre aspas, uma característica de todos os meios locais" (04/07/2008).

Já $T L 92^{\circ} E d$ veicula, em média, oito anúncios diários, que aparecem no início e no final dos blocos. Estes anúncios têm três formatos diferentes, o merchandising ${ }^{8}$, a autopromoção, e um formato semelhante ao dos anúncios veiculados nos breaks. O merchandising aparece com as logomarcas das empresas que patrocinam o telejornal. As diversas logomarcas aparecem uma atrás da outra, sobrepostas a uma imagem em movimento das principais avenidas de Buenos Aires e acompanhadas pela música da vinheta do telejornal (Figura 7).

\footnotetext{
${ }^{8}$ O merchandising consiste, conforme Reis (2008, p.65), na "inclusão do nome de um produto, de uma marca ou de uma empresa no meio da transmissão, realizada de forma expressa, com a intenção de promover o anunciante [...]”.
} 
Figura 7 - TL9: merchandising

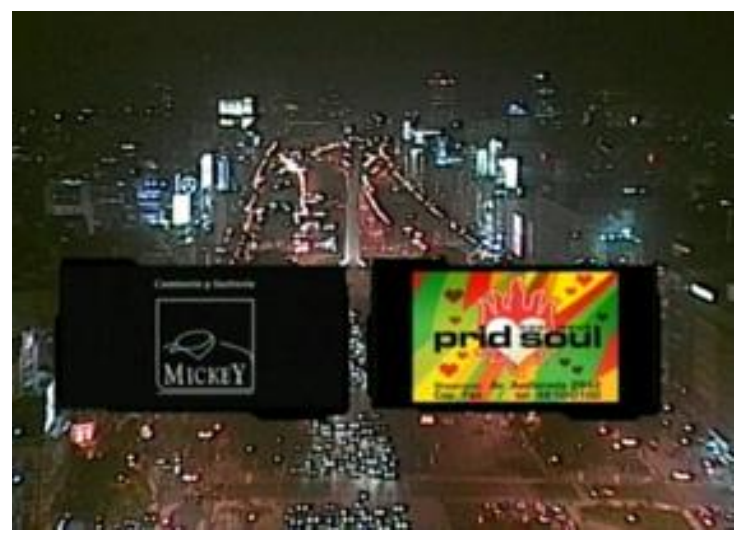

Destaca-se que a inclusão de anúncios dentro dos blocos é recurso comum a todos os telejornais, tanto no Uruguai como na Argentina. A constante presença de anúncios responde a uma tendência que busca incrementar a rentabilidade das empresas de comunicação.

A macrovisão permitiu observar também os diversos tipos de matérias utilizados nos telejornais. Na Tabela 1, apresenta-se uma média das matérias veiculadas em uma edição dos telejornais.

Tabela $1-T L M-E C$ e $T L 92^{\circ} E d$ : tipos de matérias

\begin{tabular}{|c|c|c|}
\hline $\begin{array}{c}\text { Tipo de } \\
\text { matéria } \\
\text { e Quantidade }\end{array}$ & TLM-EC & TL9 2 ${ }^{\boldsymbol{O}} \boldsymbol{d}$ \\
\hline Reportagem & $28-\mathbf{8 0 \%}$ & $13-\mathbf{7 6 , 5 \%}$ \\
\hline Nota coberta & $5-\mathbf{1 4 \%}$ & $4-\mathbf{2 3 , 5 \%}$ \\
\hline Nota simples & $1-\mathbf{3 \%}$ & - \\
\hline Entrevista & $\begin{array}{c}1-\mathbf{3 \%} \\
\text { (excepcionalmente) }\end{array}$ & - \\
\hline Comentário & $\begin{array}{c}\text { nas notas pé das } \\
\text { reportagens de esportes }\end{array}$ & nas notas pé de algumas reportagens \\
\hline Total & 35 matérias - 100\% & $17-\mathbf{1 0 0 \%}$ \\
\hline
\end{tabular}

$\mathrm{Na}$ Tabela se pode ver que, enquanto TLM-EC veicula diariamente em torno de 35 matérias, $T L 92^{\circ} E d$ veicula 17 . A explicação para essa grande diferença é que $T L 9$ trabalha muito com reportagens especiais que duram de sete a oito minutos, e TLM não tem reportagens especiais e suas matérias não superam três minutos. Nos dois casos, o tipo de matéria mais utilizado é a reportagem 
que, em TLM representa $80 \%$ do total e, em $T L 9,76,5 \%$. As notas simples e as entrevistas no estúdio somente são utilizadas pelo telejornal uruguaio. Já os comentários aparecem em ambos os telejornais, incluídos nas notas pé, porém, há uma diferença: no telejornal uruguaio, o único que faz comentários é o especialista em esportes; no argentino, os comentários são feitos pelos especialistas e, em alguns casos, pelo apresentador.

Cabe ressaltar que, nos dois telejornais, encontraram-se outros tipos de matéria. No TLM, no final de cada bloco, veiculam-se as "Noticias breves" e, no final de cada edição, há um resumo dos principais assuntos do dia, chamado "Puesta a punto". Já no TL9, há uma compilação de notícias, ou seja, um conjunto de assuntos abordados juntos, mas que não têm relação entre si e não são tratados em outro momento.

$\mathrm{Na}$ microvisão observou-se que alguns elementos são usados em ambos os telejornais do mesmo modo. Esse é o caso da escalada, chamada no TLM de "Titulares" e no TL9 de "Ventas". A escalada tem formato de nota coberta e está composta, no plano da imagem, por imagens em movimento e videografismos. Dentre os videografismos destaca-se o uso da palavra escrita como o título de um jornal. No plano sonoro, está a voz do apresentador e a música. A música na escalada é utilizada de modo diferente em cada telejornal: enquanto no TLM a música é a mesma da vinheta, no TL9, para cada assunto apresentado, há uma música diferente.

Já nos primeiros segundos de apresentação das matérias dos dois telejornais, percebem-se diferenças: TLM é apresentado por um casal e TL9 tem somente um apresentador. O cenário do telejornal uruguaio se pode ver quase em sua totalidade, pois a apresentação começa com um Plano Geral e vai se fechando nos apresentadores até chegar a um Plano Médio. O cenário do telejornal argentino praticamente não se pode ver na íntegra. O telejornal começa com um Plano Médio, fechado no apresentador, e somente se abre quando há, no estúdio, algum especialista. Aspecto comum aos telejornais é a cor utilizada nos cenários e nas logomarcas: a cor dominante nos dois casos é o azul-claro, porém, no TLM, o azul-claro está acompanhado por detalhes azul-marinho e, no $T L 9$, por detalhes alaranjados. 
Figura 8 - Cenários do $T L M$ e $T L 9$

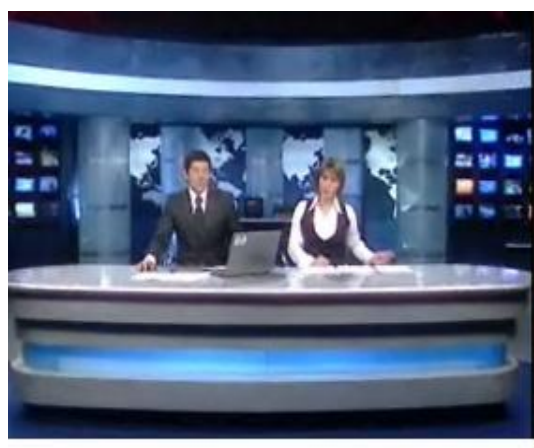

Telemundo Edición Central (Uruguai)

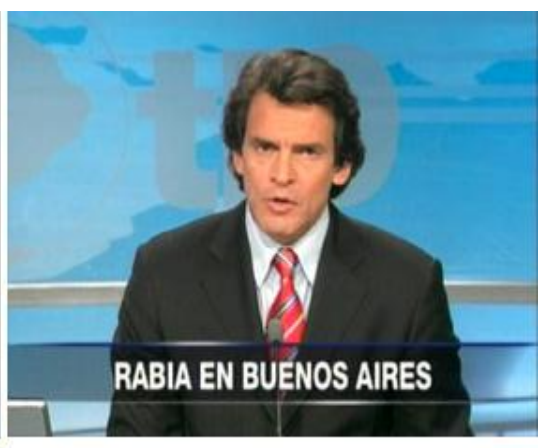

Telenueve $2^{\circ}$ Edición (Argentina)

No que diz respeito às matérias, a reportagem é o tipo mais utilizado nos dois noticiários, mas os elementos presentes nos dois casos estudados variam. No plano da imagem, enquanto o TLM praticamente não usa videografismos, o TL9 sempre recorre a eles para destacar ou acrescentar informações. O uso quase nulo dos em TLM se justifica pela falta de pessoal na equipe para produzi-los. Cada vez que o TLM quer utilizar algum videografismo, deve solicitá-lo ao departamento gráfico da emissora. Nas imagens em movimento também há diferenças. Como no $T L M$ não há um bom arquivo de imagens, utilizam-se frequentemente imagens captadas de outras emissoras. No TL9 há um bom arquivo de imagens, mas, quando não há imagens próprias sobre os assuntos abordados, praticamente não se veiculam imagens de outras emissoras. Esse telejornal recorre a imagens de câmeras de segurança, de telefones celulares e até baixadas da Internet. No plano sonoro das reportagens, a diferença mais marcante é o uso da música: no TLM praticamente não há música, no TL9, ela está sempre presente. Outro aspecto divergente nas reportagens é o uso dos links ao vivo que, no TLM se utilizam em poucas ocasiões, mas no TL9 têm presença diária.

Da observação dos atores verificou-se que, nos dois telejornais os apresentadores chamam a audiência de "você", buscando gerar relação de intimidade. Nesses telejornais, não há comentaristas, há presença diária dos especialistas, que, além de comentar as matérias, as apresentam. De certa forma, os telejornais introduzem uma pluralidade de vozes na apresentação. No TL9, além dos especialistas, os repórteres que produzem as reportagens especiais, muitas vezes, vão ao estúdio e apresentam as matérias junto ao apresentador; os repórteres também têm presença marcante, seus rostos aparecem em praticamente todas as reportagens e, em muitos casos, aparecem no estúdio. Já no TLM, os repórteres nem sempre aparecem, há impessoalidade maior. Outro ator 
presente nestes noticiários é o locutor impessoal, ele é nos dois casos, uma marca característica dos telejornais.

\section{Considerações Finais}

$\mathrm{O}$ estudo demonstrou que, na estrutura dos dois telejornais analisados, encontram-se os mesmos elementos, porém, o modo como são usados varia, e esse modo marca a diferença. O estudo também permitiu comprovar que não há um modo platino de fazer telejornais, pois os dois produtos analisados são bastante diferentes.

Essas diferenças explicam-se, em primeiro lugar, pelas diferentes soluções encontradas pelos telejornais para resolver os mesmos problemas. Por exemplo, enquanto TLM usa imagens captadas de outras emissoras, TL9 recorre a imagens de menor qualidade captadas com outros recursos.

Em segundo lugar, o que distancia um telejornal do outro é a disponibilidade econômica. Apesar de nenhum dos telejornais divulgar seu orçamento, ele fica evidente na equipe de profissionais e nos equipamentos disponíveis. O investimento na produção desses dois telejornais se revela na redação. Enquanto o telejornal uruguaio trabalha com 50 profissionais, entre jornalistas e técnicos, para produzir quatro edições, o telejornal argentino trabalha com 150 profissionais, entre jornalistas e técnicos, para produzir a mesma quantidade de edições diárias. Essa diferença nota-se principalmente na quantidade de reportagens especiais que produz o TL9, enquanto o TLM não produz nenhuma, e em todos os elementos presentes nas reportagens, como, por exemplo, os videografismos, a música, que é quase nula no telejornal uruguaio e marcante no argentino.

Contudo, o fato de ter maior ou menor orçamento não significa fazer melhor ou pior telejornal, do ponto de vista jornalístico. TLM é o telejornal com menores recursos técnicos, menor equipe de produção, o que produz matérias mais curtas e o mais sério. Já o telejornal argentino possui maiores recursos e suas matérias são mais longas e sofisticadas, no que se refere aos recursos audiovisuais utilizados, mas está muito ligado ao show, ao entretenimento. A explicação disso encontra-se no início, com a veiculação dos primeiros telejornais no país, em 1954, quando a apresentação das notícias estava acompanhada por fantoches, "secretárias" lindas e humor. De lá pra cá, todos os telejornais argentinos sempre caminharam no limite entre o entretenimento e o jornalismo, portanto, a relação que o TLM e o TL9 têm com o jornalismo explica-se na intenção, em seu objetivo, independentemente do orçamento e das disponibilidades técnicas e de profissionais. 
Em terceiro lugar a diferença entre $T L M$ e $T L 9$, está no modo de encarar as matérias. No TLM não se trabalha com reportagens especiais, e no $T L 9$ elas estão sempre presentes. As reportagens especiais supõem dedicação maior na produção e edição, assim como uso maior dos recursos disponíveis.

Em quarto lugar, as diferenças entre os telejornais explicam-se pelo contexto. De acordo com Fiske e Hartley "a televisão é uma construção humana e o trabalho é o resultado das escolhas humanas, decisões culturais e pressões sociais. A mídia responde às condições em que ela existe" (2005, p.5). O Uruguai é um país conservador e politizado. A televisão do país nasceu e se desenvolveu nas mãos de grupos privados, e três das quatro emissoras são, e sempre foram, empresas familiares. O investimento em produção própria é mínimo e, com o advento da televisão a cabo, todas as emissoras apostaram em seus telejornais como diferencial. A Argentina também é um país politizado, mas de modo diferente. A opinião do povo se sente na rua, nos "piquetes". A televisão do país surgiu do investimento público, das mãos de Evita Perón, mas em seguida surgiram as emissoras privadas. Atualmente, há cinco emissoras, e só uma é pública. Todas possuem produção própria: telenovelas, programas de entretenimento, telejornais etc. Os telejornais argentinos, desde o início, caminham na linha tênue entre o jornalismo e o entretenimento, e isso fica claro hoje na seleção das matérias e na forma como elas são apresentadas: muita música, muitos planos, muitos videografismos.

Assim, dois países aparentemente tão próximos geograficamente e, em alguns sentidos, tão parecidos, apresentam uma diversidade de visões, de modos de produzir e (re) construir a realidade.

\section{Referências}

ARONCHI, José Carlos de Sousa. Gêneros e formatos na televisão brasileira. São Paulo: Summus, 2004.

ÁLVAREZ, Luciano. La casa sin espejos: perspectivas de la industria audiovisual uruguaya. Montevideo: Editorial Fin de Siglo, 1993.

BAKHTIN, Mikhail. Estética da criação verbal. São Paulo: Martins Fontes, 1992.

CEBRIÁN, Mariano. La información en televisión: obsesión mercantil y política. Barcelona: Gedisa, 2004.

CEBRIÁN, Mariano. Géneros informativos audiovisuales. Madrid: Editorial Ciencia 3. S.A., 1992.

CEBRIÁN, Mariano. La información audiovisual: un servicio a la sociedad. Madrid: Ediciones Forja S.A., 1983. 
CEBRIÁN, Mariano. Introducción al lenguaje de la televisión: una perspectiva semiótica.

Madrid: Pirámide, 1978.

CHARADEAU, Patrick. Discurso das mídias. São Paulo: Contexto, 2006.

CHION, Michel. La audiovisión: introducción a un análisis conjunto de la imagen y el sonido.

Barcelona: Paidós, 1993.

FISKE, John; HARTLEY, John. Reading television. 2.ed. New York: New Accents, 2005.

GROTH, Otto. Tarefas da pesquisa da ciência da cultura. In: MAROCCO, B.; BERGER, C.

(Orgs.). A era glacial do Jornalismo. Porto Alegre: Sulina, 2006, p.183-306.

JAKOBSON, Roman. Lingüística e comunicação. São Paulo: USP-Cultrix, 1969.

LAGE, Nilson. Linguagem Jornalística. 6. ed. São Paulo: Ática, 1998.

MARQUES DE MELO, José. Comunicação social: teria e pesquisa. Rio de Janeiro: Vozes, 1972.

MEDITSCH, Eduardo. O rádio na era da informação: teoria e técnica do novo radiojornalismo.

Florianópolis: Insular- Ed. da UFSC, 2001.

PORTUGAL. Lei n. 27/2007, de 30 de julho de 2007. Decreta sobre regulamentação e acesso à actividade de televisão e o seu exercício. Lex: Diário da República, Lisboa, 1. ${ }^{a}$ série, n.145, 30 de julho de 2007. Disponível em: 〈http://ww1.rtp.pt/wportal/grupo/pdf/lei_n27_2007_30junho.pdf〉. Acesso em: 1 maio 2009.

REIS, Clóvis. Propaganda no rádio: os formatos de anúncio. Blumenau: EDIFURB, 2008. PEREIRA JÚNIOR, Alfredo Eurico Vizeu; PORCELLO, Flávio A. Camargo; MOTA, Célia Ladeira (Orgs.). Telejornalismo: a nova praça pública. Florianópolis: Insular, 2006a.

PEREIRA JÚNIOR, Alfredo Eurico Vizeu. Telejornalismo: cotidiano e lugar de segurança. Revista Estudos em Jornalismo e mídia, Florianópolis: Posjor UFSC-Insular, v.3, n.1, p.103-113, $1^{\circ}$ semestre, 2006b.

PEREIRA JÚNIOR, Alfredo Eurico Vizeu. O lado oculto do telejornalismo. Florianópolis:

Calandra, 2005a.

PEREIRA JÚNIOR, Alfredo Eurico Vizeu. Decidindo o que é notícia: os bastidores do telejornalismo. 4.ed. Porto Alegre: EDIPUCRS, $2005 \mathrm{~b}$. 